\title{
PARAÍSOS FISCAIS: ASPECTOS POSITIVOS E NEGATIVOS
}

\section{ARTIGO DE REVISÃO}

OJEDA, Nataly Luiza Nantes ${ }^{1}$

OJEDA, Nataly Luiza Nantes. Paraísos fiscais: Aspectos positivos e negativos. Revista Científica Multidisciplinar Núcleo do Conhecimento. Ano 05, Ed. 12, Vol. 03, pp. 69-80. Dezembro de 2020. ISSN: 2448-0959, Link de acesso: https://www.nucleodoconhecimento.com.br/contabilidade/paraisos-fiscais

\section{RESUMO}

Este artigo tem a finalidade de desvendar os Paraísos Fiscais e sua crescente utilização, sabe-se que a operação tem causado queda na arrecadação e por consequência o bloqueio do desenvolvimento econômico dos países. Os objetivos giram em torno da análise dos aspectos positivos e negativos, considerando que existem aqueles que se usufruem das benesses oferecidas pelos paraísos fiscais, bem como existem aqueles que são prejudicados por essa prática, abrangendo seus conceitos, usuários, passando por uma breve explicação do modo de funcionamento os fluxos de capitais no mundo, as consequências do aumento desse tipo de transação para os estados. A metodologia possui abordagem qualitativa através de pesquisa exploratória de natureza bibliográfica descritiva com o intuito de demonstrar os problemas decorrentes da utilização de paraísos fiscais por pessoas físicas e jurídicas. Muito tem sido feito para evitar as consequências negativas da utilização dos paraísos fiscais por meio do BEPS em conjunto com o ICRICT que formulam diretrizes a serem implementadas para redução da erosão das bases tributárias dos estados, os aspectos negativos se caracterizam pela perda do poder estatal para a promoção e continuidade dos serviços básicos e bem como o perecimento de investimentos em políticas públicas que combatam problemas

\footnotetext{
${ }^{1}$ Graduada em Ciências Contábeis (2011) e em Direito (2018), com especialização em Gestão Pública área de concentração em Administração Pública (2019).
} 
sociais, como fome, desemprego, criminalidade, saúde, educação entre outros. Por outro lado, o termo "paraíso fiscal" apesar de ser comumente visto com certa aversão pela mídia, sociedade em geral e países, numa ótica existem aspectos positivos pois sua utilização é uma ferramenta operacional do planejamento tributário financeiro e comercial, o aumento nos lucros pode galgar novas oportunidades de negócio, sendo que estes negócios podem gerar mais empregos e renda aos mais pobres.

Palavras-chave: paraísos fiscais, evasão fiscal, elisão fiscal, BEPS, ICRICT.

\section{INTRODUÇÃO}

Paraísos Fiscais são associados historicamente e principalmente através da mídia televisiva, ao capital ilícito, onde seria possível ocultar recursos financeiros oriundos de ilegalidades, porém também podem ser utilizados por bilionários e empresas transnacionais para driblar os tributos e aumentar suas fortunas de forma perfeitamente lícita.

Atualmente inexistem maneiras eficazes para impedir que as pessoas físicas e jurídicas transfiram lucros para países com baixos impostos, vez que o sistema internacional de tributação, que é o mesmo desde os anos de 1920, ou seja, há cem anos o mundo utiliza-se das mesmas normas regulamentadoras.

Para evitar o enfraquecimento massivo na arrecadação dos estados a OCDE e o G20 criaram um programa que ficou conhecido como BEPS (Base, Erosion, Profit, Shifting), aliado ao BEPS existe ainda um grupo de especialistas que se organizou para monitorar o debate sobre a tributação internacional e propor alternativas ao modelo da OCDE.

Posto isso, o presente artigo tem por objetivo problematizar os aspectos positivos e negativos da utilização dos paraísos fiscais. 


\section{REFERÊNCIAL TEÓRICO}

\subsection{O QUE É PARAÍSO FISCAL?}

Paraísos fiscais são áreas comerciais livres da cobrança de impostos ou com taxas próximas a zero sobre as transações financeiras, caracteriza-se pela ausência de tributação, garantias de sigilo bancário e identidade dos investidores, o que faz delas um esconderijo perfeito para pessoas físicas e jurídicas que desejam omitir os seus lucros.

Tais características, fazem com que países que as proporcionem tenham sido associados historicamente, principalmente na mídia televisiva, ao capital ilícito, onde seria possível ocultar recursos financeiros oriundos de crimes como exemplo: corrupção e tráfico de drogas e de pessoas, sem quaisquer questionamentos, conforme leciona (DE SÁ, 2016) "Os paraísos fiscais são vistos como uma forma de incentivo para atividades ilícitas, e no estudo em particular, visto como um instrumento para atividades corruptas."

A este respeito, discorre o autor "Os paraísos fiscais são geralmente vistos com preconceito pelas pessoas e até mesmo pelos governos de alguns países, incluindo o Brasil ..." (DE MELLO, 2014), sobre o preconceito que circunda o tema, existem aqueles que se usufruem das benesses oferecidas pelos paraísos fiscais, bem como existem aqueles que são prejudicados por essa conduta, assim discorrem os autores (REIS e LOEBENS, 2019) "Os maiores prejudicados são os Estados que perdem a riqueza gerada

em

seus territórios e perdem sua arrecadação tributária, e consequentemente também é prejudicada a grande maioria da população destes Estados ..." a respeito da queda a arrecadação e por consequência o bloqueio do desenvolvimento econômico dos países.

Dadas as definições e suas diferentes vertentes cabe a busca de identificação dos usuários, as movimentações financeiras realizadas em paraísos fiscais são feitas por pessoas físicas e jurídicas "...Os paraísos fiscais permitem que indivíduos e firmas 
ocultem informações sobre suas atividades..." grifo nosso (SNF e GFI et al., 2015), representados por bilionários e empresas transnacionais para driblar os tributos e aumentar suas fortunas.

\subsection{DESVENDANDO O FLUXO DE CAPITAIS NO MUNDO}

Por mais que os países de todo o mundo possuam seus sistemas próprios de cobrança de tributos, existem regras internacionais que regulam a circulação do dinheiro entre os países, o problema é estas tais normas internacionais entraram em vigor a cerca de um século em mercados bem menos globalizados que os de hoje em dia, em razão disso existe determinada defasagem que acabou gerando brechas e lacunas nas regras que regulam o trânsito de capital, ou seja, de dinheiro pelo mundo.

Tais brechas na legislação consentem que empresas transnacionais e multimilionários (pessoas físicas e jurídicas) utilizem manobras fiscais ou ilegais para ocultar ganhos e evadir-se do pagamento de tributos, e um dos principais mecanismos para isso seja possível, é a existência e utilização dos paraísos fiscais, diante desse cenário, as autoridades internacionais cada dia mais são pressionadas a criar um novo sistema internacional de tributação, que é o mesmo desde os anos de 1920, assim narra (PRZEPIORKA, 2018) "...a partir da década de 1920, pode-se afirmar que se consolidou o modelo de tributação internacional desenvolvido a partir dos trabalhos de Bruins, Stamp, Seligman e Eunadi...".

Atualmente não existem maneiras eficazes para impedir que as pessoas físicas e jurídicas transfiram lucros para países com baixos impostos, conclui o autor (PRZEPIORKA, 2018) "Os tradicionais elementos de conexão cristalizados no sistema jurídico internacional desde o início do século XX já não se prestam mais a orientar as políticas fiscais internacionais no ambiente globalizado." Considerando ainda que ao longo desses 100 anos, as empresas multinacionais desenvolveram uma expertise sem precedentes para tornar mínima a pressão fiscal internacional, e prosseguir em sua manobra para multiplicar seus ganhos, o autor DALMOLIN descreve dados estarrecedores de mensuração de valores: 
Recentemente o Banco Central do Brasil (2018) divulgou o censo de capitais brasileiros no exterior. Esses dados revelaram que 60.301 pessoas (55.757 pessoas físicas e 4.544 pessoas jurídicas) possuem quase um trilhão de dólares aplicados no exterior (aproximadamente $25 \%$ do PIB). (DALMOLIN, 2018).

Nesse contexto a OCDE e o G20 criaram um programa que ficou conhecido como BEPS (Base, Erosion, Profit, Shifting) MÉLO e PIMENTEL assim descrevem:

Impulsionada pela crise econômica de 2008, da qual muitos países desenvolvidos ainda não se recuperaram por completo, a Organização para Cooperação e Desenvolvimento Econômico (OCDE), em conjunto com o Grupo dos 20 (G-20), lançou, em 2013, um Plano de Ação visando coibir o desvio de lucros e a erosão de bases tributáveis, programa que passou a ser conhecido como Base Erosion and Profit Shifting (BEPS). (MÉLO e PIMENTEL, 2016).

A tradução significa "...erosão da base e transferência de lucros." (NUNES, HALIK et al. 2017), o seu intuito consiste em combater a fuga de capitais e retomar a capacidade de arrecadação dos países.

\subsection{BEPS E ICRICT}

Em linhas gerais, por meio do BEPS foram criadas medidas que aprimoram aspectos técnicos, administrativos, e sobretudo aumentam a transparência das empresas na publicação de seus balanços financeiros.

Mas ainda que a iniciativa tenha sido bastante celebrada como primeiro passo em direção ao combate da evasão, as respostas ainda passam longe de resoluções concretas para o problema, foi a partir dessa observação que um grupo de quinze especialistas se organizou para monitorar o debate sobre a tributação internacional e propor alternativas ao modelo da OCDE, a agremiação ficou conhecida como ICRICT.

ICRICT é a Comissão Independente pela Reforma da Taxação Corporativa Internacional que tem como objetivo promover o debate sobre a reforma tributária nas sociedades em nível internacional mediante uma discussão que seja a mais ampla e includente possível das normas fiscais internacionais; considerar as reformas desde a perspectiva do interesse público mundial em vez do nacional; e buscar 
soluções fiscais justas, eficazes e sustentáveis para o desenvolvimento. Grifo do autor (IJF, 2016).

A comissão do ICRICT reúne diversos especialistas como exemplo vencedor do prêmio Nobel de economia e ex chefe do banco mundial Joseph Stiglitz e do economista e escritor francês Thomas Piketty, este grupo propõe, por exemplo, que as normas propostas pelo BEPS, deveriam ser discutidas e analisadas na Organização das Nações Unidas (ONU) como forma de democratizar o debate sobre a temática em questão.

Isso se deve ao número restrito de países que elaborou o programa acabou gerando uma sub representação dos interesses das nações mais pobres, por exemplo, um dos avanços mais claros propostos no BEPS é a criação de uma legislação que obrigue empresas multinacionais a divulgar suas demonstrações financeiras país por país:

A Declaração País-a-País, instituída no Brasil através da IN 1.681/16, é fruto de uma cooperação internacional atrelada às ações propostas no âmbito do Projeto BEPS (Base Erosion and Profit Shifting ou Erosão da Base Tributável e Transferência de Lucros), coordenado conjuntamente pelos países-membro do G-20 e pela OCDE (Organização para a Cooperação e o Desenvolvimento Econômico). (GO FURTHER, 2017).

A medida provocaria a simplificação da fiscalização de eventuais manobras fiscais praticadas pelas empresas, ou seja, maior transparência:

... valendo-se da discussão existente sobre práticas de cooperação e transparência fiscal que permitissem a obtenção de informações relevantes que possam aumentar a efetividade das atividades de fiscalização, tentar aumentar os limites impositivos à elisão tributária. (BARRETO e TAKANO, 2016).

No entanto a proposta acabou sendo atenuada por outras duas cláusulas, a primeira estabelece que somente o país de origem da multinacional, terá acesso aos relatórios contábeis, sem obrigação de compartilhar a informação com os outros países, a segunda determina que apenas somente as empresas com lucros anuais superiores a 750 milhões de euros são obrigadas a divulgar tais dados,, vejamos:

Art. 4ํㅡㄹ Estão dispensadas da entrega da Declaração País-a-País as entidades integrantes residentes no Brasil cuja receita consolidada total 
do grupo multinacional no ano fiscal anterior ao ano fiscal de declaração, conforme refletido nas demonstrações financeiras consolidadas do controlador final, seja menor que:

I - R \$2.260.000.000,00 (dois bilhões, duzentos e sessenta milhões de reais), se o controlador final for residente no Brasil para fins tributários; ou

II - $€ 750.000 .000,00$ (setecentos e cinquenta milhões de euros), ou o equivalente convertido pela cotação de 31 de janeiro de 2015 para a moeda local da jurisdição de residência para fins tributários do controlador final. (IN 1.681/2016).

Na prática isso limita o poder de fiscalização dos países mais pobres e exclui da lista de obrigações do BEPS cerca de $90 \%$ das multinacionais.

Em contrapartida, o ICRICT argumenta que o aumento real da transparência, deveria ampliar essa obrigação para a totalidade de empresas que possuam recursos em paraísos fiscais, e tornar os dados acessíveis para todos os estados, sem quaisquer limitações, assim descreve "... exigir publicação de relatórios país por país para todas as empresas que se beneficiam do apoio do Estado." (IJF, 2020).

O ICRICT faz também outras propostas que procuram corrigir distorções nas regras da tributação internacional, mas à medida que ganhou maior centralidade no programa está na criação de um novo modelo de taxação das multinacionais.

A utilização de paraísos fiscais já foi identificada em empresas como Google, Starbucks e Amazon:

A divisão da Amazon no Reino Unido, por exemplo, registrou vendas de mais de US $\$ 8$ bilhões no ano fiscal passado, mas pagou US $\$ 18,1$ milhões em impostos.

O Google, por sua vez, alcançou faturamento de US \$5,5 bilhões em 2013 , ano em que pagou US $\$ 17,6$ milhões em impostos.

Mas uma das empresas mais questionadas foi a Starbucks, que em 2012 relatou vendas de mais de US $\$ 600$ milhões, mas pagou zero impostos corporativos. Grifo nosso (BBC, 2015) 
Tais empresas movimentam grandes quantias de dinheiro realizando manobras fiscais que driblam o pagamento de tributos, e consequentemente inflam seus ganhos em paraísos fiscais.

Para contornar esse quadro, o documento elaborado pelo ICRICT, propõe uma resolução aparentemente simples, porém com grandes perspectivas de transformação: reconhecer as multinacionais como entidades únicas, essa mudança colocaria fim a esse tipo de prática, pouco importa se a companhia possui negócios de fachada em paraísos fiscais, já que os lucros da empresa passariam a ser calculados globalmente.

A Comissão tem como objetivo promover o debate sobre a reforma por meio de uma discussão mais ampla e abrangente das regras tributárias internacionais do que é possível em qualquer outro fórum existente; considerar reformas a partir de uma perspectiva de interesse público global e não de vantagem nacional; e buscar soluções tributárias justas, eficazes e sustentáveis para o desenvolvimento. (IJF, 2020).

Tendo isso por base, a ideia dos economistas, é determinar qual valor será tributado, a partir de parâmetros materiais, como por exemplo: vendas, número de funcionários ou de plantas produtivas, e por fim o projeto propõe a criação de uma divisão proporcional dos impostos arrecadados, as regiões que concentram mais atividades recebem mais e as regiões que concentram menos atividades recebem menos.

\section{METODOLOGIA}

A metodologia apresentada possui abordagem qualitativa já que o método adotado foi através de pesquisa exploratória de natureza bibliográfica descritiva com o intuito de demonstrar os problemas decorrentes da utilização de paraísos fiscais por pessoas físicas e jurídicas.

A pesquisa bibliográfica foi realizada de forma sintetizada onde foram selecionados artigos, periódicos, teses e dissertações que abordavam conceitos sobre os paraísos fiscais contidas nos bancos de dados eletrônicos. 
As buscas foram realizadas no Google Acadêmico e na Scientific Electronic Library Online (SciELO), os descritores empregados nestas bases, em português foram: "paraísos fiscais", "evasão fiscal", "elisão fiscal", "BEPS", "ICRICT". O período de publicação dos estudos foi de 2012 até novembro de 2020.

E ainda, de forma complementar foi realizada a coleta em bases teóricas da literatura acadêmico-científica (livros, revistas e relatórios) voltadas para o tema em proposto.

\section{DISCUSSÕES SOBRE OS ASPECTOS POSITIVOS E NEGATIVOS AO USO DE PARAÍSOS FISCAIS}

Atualmente de forma inédita em nossa história, 2.153 pessoas detém mais de riqueza que a 4,6 bilhões de pessoas, de acordo com os dados da (OXFAM, 2020), não há dúvida que projetos como BEPS, merecem mérito pelo pioneirismo no foco em combater os paraísos fiscais e na identificação desse problema como um dos principais empecilhos para redução das desigualdades sociais, mas é consenso na comunidade internacional que a urgência pela resolução desses conflitos exige políticas mais incisivas que fortaleçam o poder de arrecadação dos estados e auxiliem o processo de distribuição de riquezas, sem isso, a tendência é que os próximos anos mantenham o padrão de concentração de renda, visto nas últimas décadas, a população paga as contas da recessão enquanto uma minoria poderosa, surfa em benefícios tributários, fugindo de impostos e omitindo seus ganhos.

Por outro lado o termo "paraíso fiscal" é comumente visto com certa aversão pela mídia, sociedade em geral e países, que frequentemente tentam manter rigorosos controles e repressão às pessoas físicas e jurídicas que se utilizam destes locais para realizar investimentos e operações mercantis, quando na verdade o termo, pode ser, numa ótica mais ampla, apenas uma ferramenta operacional do planejamento tributário, assim descreve (RAMOS, 2019) "Paraíso Fiscal, na acepção do termo, não significa e não nos remete à prática criminosa. Eles servem ainda como "condutos" em operações financeiras internacionais e na montagem do planejamento tributário.", afinal os valores aplicados em paraísos fiscais não são em sua totalidade oriundos de atividades ilícita e o combate a sua utilização pode representar prejuízos ao progresso 
e a expansão do mercado globalizado, assim como os planejamentos tributário, financeiro e comercial:

Vale lembrar que, por planejamento tributário, se entende aquele conjunto de sistemas legais que visam diminuir o pagamento de tributos; assim, qualquer contribuinte tem o direito de estruturar os seus negócios da maneira que lhe pareça mais oportuna, procurando a diminuição dos custos, inclusive dos tributos incidentes sobre a renda auferida em seus negócios. Se esta pessoa ou empresa fizer isso de forma lícita, as autoridades devem respeitá-lo, não podendo se pensar em obrigar as pessoas a pagar o máximo de impostos possível aos seus respectivos Governos. Aliás, é sabido que, com a globalização da economia, tornouse questão de sobrevivência a correta administração do ônus tributário, com o intuito de minimizá-lo legalmente. (DE MELLO, 2014).

Em outras palavras, sustenta o autor grande parte das operações mercantis e financeiras realizadas em paraísos fiscais é permitida por lei.

\section{CONSIDERAÇÕES FINAIS}

O grande problema da saída de recursos dos países com alta carga tributária destinados aos paraísos fiscais, é erosão das bases tributárias dos estados, que pode ocasionar perda do poder estatal para a promoção e continuidade dos serviços básicos e bem como o perecimento de investimentos em políticas públicas que combatam problemas sociais, como fome, desemprego, criminalidade, saúde, educação entre outros.

A dificuldade de identificar a rota do dinheiro e a falta de transparência das empresas são grandes impasses para o combate e a fiscalização da utilização de paraísos fiscais, por outro lado, paraíso fiscal não é sinônimo de ilicitude, e qualquer cidadão ou empresário pode vir a investir licitamente seu patrimônio ou seus ativos financeiros em outros países normalmente onde seus lucros podem galgar novas oportunidades de negócio, sendo que estes negócios podem gerar mais empregos e renda aos mais pobres.

Quanto ao Brasil, cumpre ainda destacar que é preciso que haja a formulação de políticas voltadas para a manutenção de recursos financeiros sem que isso importe 
em ofensa a Carta Magna (BRASIL, 1988), que claramente permite em seu artigo 5ㄴ, $\mathrm{XV}$, a liberdade de locomoção no território nacional, entrar, permanecer e sair com seus bens, logo, por mais que o Fisco e a sociedade em geral sejam lesados com essa manobra não pode haver proibição ou limitação em relação a saída de recursos e ativos financeiros do território nacional, pois constituem uma estratégia de planejamento fiscal revestida de legalidade.

\section{REFERÊNCIAS BIBLIOGRÁFICAS}

BARRETO, Paulo Ayres, TAKANO, Caio Augusto. Os desafios do planejamento tributário internacional na era pós-BEPS. In XIII Congresso - 50 anos do código tributário nacional, IBET, 2016. Disponível em https://www.ibet.com.br/wpcontent/uploads/2017/09/BEPS.pdf. Acesso em 15 nov. 2020.

BRASIL. Dispõe sobre a obrigatoriedade de prestação das informações da Declaração País-a-País. Instrução Normativa RFB № 1681, DE 28 DE DEZEMBRO DE 2016.2 Disponível em: http://normas.receita.fazenda.gov.br/sijut2consulta/link.action?idAto=79444. Acesso em 20 nov. 2020.

BRASIL. Constituição (1988). Constituição da República Federativa do Brasil. Disponível em http://www.planalto.gov.br/ccivil_03/constituicao/constituicao.htm. Acesso em 20 nov. 2020.

BBC, World. As pessoas que "deixaram" o País de Gales para evitar o pagamento de impostos no Reino Unido. Notícia de 12 de novembro de 2015. Disponível em https://www.bbc.com/mundo/noticias/2015/11/151112_economia_crickhowell_pueblo _gales_paraiso_fiscal_ch. Acesso em 20 nov. 2020.

DALMOLIN, Luís Carlos. A exploração tributária intermediada pelo estado: dos mecanismos tributários anestesiantes à fictio juris, Dissertação (Mestrado), Junho de 2016, Disponível em https://lume.ufrgs.br/handle/10183/187387. Acesso em 13 nov. 2020. 
DE MELLO, Antônio C. T, Paraísos Fiscais e Estratégias Empresariais: Ensaios sobre Investimentos Offshore. Novembro 2014, Edição do Kindle.

DE SÁ, Daniel Ferreira, Paraísos Fiscais, Corrupção e Crescimento Econômico, Dissertação (Mestrado) Faculdade de Economia do Porto - junho de 2016. Disponível em https://repositorioaberto.up.pt/bitstream/10216/86744/2/158522.pdf. Acesso em 12 nov. 2020.

GO FURTHER. Declaração país - a país e ação 13 do BEPS no Brasil. In Boletim Informativo, 04 de julho de 2017. Disponível em http://www.gofurthergroup.com.br/declaracao-pais-pais-e-acao-13-do-beps-nobrasil/\#: :text=A\%20Declara\%C3\%A7\%C3\%A30\%20Pa\%C3\%ADs\%2Da\%2DPa\%C 3\%ADs,G\%2D20\%20e\%20pela\%20OCDE. Acesso em 14 nov. 2020.

IJF, Instituto Justiça Fiscal. Declaração da ICRICT, 20 de abril de 2016, Disponível em https://ijf.org.br/declaracao-da-icrict/. Acesso em 14 nov. 2020.

IJF, Instituto Justiça Fiscal. ICRICT demanda medidas tributárias internacionais para uma recuperação econômica sustentável, 16 de junho de 2020, Disponível em https://ijf.org.br/icrict-demanda-medidas-tributarias-internacionais-para-umarecuperacao-economica-sustentavel/. Acesso em 20 nov. 2020.

MÉLO, Luciana Grassano de Gouvêa, PIMENTEL, João Otávio Martins. O plano de ação beps e as mudanças de paradigmas na tributação, Revista Acadêmica Faculdade de Direito do Recife, Volume 88, número 2, julho/dezembro de 2016. Disponível em https://www.periodicos.ufpe.br. Acesso em 10 nov. 2020.

NUNES, André, HALIK, Aline Roberta et al. A redução da evasão fiscal com a adoção do BEPS - Base Erosion and Profit Shifting, dezembro de 2016, Revista Espacios Volume 38, o 23 Ano 2017, Página 6. Disponível em: https://www.revistaespacios.com/a17v38n23/a17v38n23p06.pdf. Acesso em 18 nov. 2020. 
PRZEPIORKA, Michell. Possibilidade de tributação em bases territoriais no sistema jurídico brasileiro - ofensa ao princípio da universalidade? - Revista Direito Tributário Internacional Atual, n. 4 (2018), Disponível em: https://www.ibdt.org.br/RDTIA/n-4-2018/possibilidade-de-tributacao-em-basesterritoriais-no-sistema-juridico-brasileiro-ofensa-ao-principio-da-universalidade/. Acesso em 16 nov. 2020.

RAMOS, Samuel Ebel Braga. A lavagem de dinheiro por meio de paraísos fiscais como crime transnacional: a cooperação internacional na recuperação de ativos. Revista Jurídica da Escola Superior de Advocacia da OAB-PR Ano 4 - Número 2 - Outubro de 2019. Disponível em http://revistajuridica.esa.oabpr.org.br/wpcontent/uploads/2019/10/revista-esa-10-cap-06.pdf. Acesso em 20 nov. 2020.

REIS, Arthur Harder, LOEBENS, João Carlos. A omissão das nomenclaturas tributárias:

um breve

estudo sobre os "paraísos fiscais. 2019. Disponível em: https://ijf.org.br/a-omissao-das-nomenclaturas-tributarias-um-breve-estudo-sobre-osparaisos-fiscais/. Acesso em: 12 nov. 2020.

SNF e GFI, Centro de Pesquisa Aplicada-Escola de Economia da Noruega; Global Financial Integrity et al. Fluxos Financeiros e Paraísos Fiscais: Uma Combinação para Limitar a Vida de Bilhões de Pessoas, dezembro de 2015, Disponível em: https://www.globaltaxjustice.org/sites/default/files/FluxoFinanceiroFINAL.pdf. Acesso em 17 nov. 2020.

OXFAM. Bilionários do mundo têm mais riqueza do que $60 \%$ da população mundial. Documento Informativo da Oxfam Brasil, 19 de janeiro de 2020. Disponível em: https://www.oxfam.org.br/noticias/bilionarios-do-mundo-tem-mais-riqueza-doque-60-da-populacao-mundial/. Acesso em 21 nov. 2020

Enviado: Novembro, 2020.

Aprovado: Dezembro, 2020. 